University of Nebraska - Lincoln

DigitalCommons@University of Nebraska - Lincoln

1995

Remote sensing of chlorophyll in Lake Kinneret using

highspectral- resolution radiometer and Landsat TM: spectral features of reflectance and algorithm development

Yosef Z. Yacobi

Yigal Allon Kinneret Limnological Laboratory

Anatoly Giltelson

Ben-Gurion University of the Negev

Meir Mayo

Tel Aviv University

Follow this and additional works at: https://digitalcommons.unl.edu/natrespapers

Part of the Natural Resources and Conservation Commons

Yacobi, Yosef Z.; Giltelson, Anatoly; and Mayo, Meir, "Remote sensing of chlorophyll in Lake Kinneret using highspectral- resolution radiometer and Landsat TM: spectral features of reflectance and algorithm development" (1995). Papers in Natural Resources. 288.

https://digitalcommons.unl.edu/natrespapers/288

This Article is brought to you for free and open access by the Natural Resources, School of at DigitalCommons@University of Nebraska - Lincoln. It has been accepted for inclusion in Papers in Natural Resources by an authorized administrator of DigitalCommons@University of Nebraska - Lincoln. 


\title{
Remote sensing of chlorophyll in Lake Kinneret using high- spectral-resolution radiometer and Landsat TM: spectral features of reflectance and algorithm development
}

\author{
Yosef Z.Yacobi, Anatoly Gitelson ${ }^{1,3}$ and Meir Mayo ${ }^{2}$ \\ Israel Oceanographic \& Limnological Research, Yigal Allon Kinneret \\ Limnological Laboratory, PO Box 345, Tiberias 14102, ${ }^{1}$. Blaustein Institute for \\ Desert Research, Ben-Gurion University of the Negev, Sede Boker 84990 and \\ ${ }^{2}$ Department of Geophysics and Planetary Science, Tel-Aviv University, Israel
}

${ }^{3}$ To whom correspondence should be sent

\begin{abstract}
High-resolution reflectance spectra in the range of 400-850 nm were obtained from Lake Kinneret during a period when dense populations of the dinoflagellate Peridinium gatunense dominated the phytoplankton. Chlorophyll (Chl) concentrations ranged from 5.1 to $185 \mathrm{mg} \mathrm{m}^{-3}$ and from 2.4 to $187.5 \mathrm{mg} \mathrm{m}^{-3}$ in the samples of two independent experiments. The most prominent features of the reflectance spectra were: (i) a wide minimum from 400 to $500 \mathrm{~nm}$; (ii) a maximum at 550-570 nm, which did not surpass $3 \%$ in samples with high $\mathrm{Chl}$ concentration $\left(>20 \mathrm{mg} \mathrm{m}^{-3}\right)$, indicating a strong absorption by pigments in the green range of the spectrum; (iii) a minimum at $676 \mathrm{~nm}$; this was $\sim 1 \%$ and was almost insensitive to variation in Chl concentration $>10 \mathrm{mg} \mathrm{m}^{-3}$; (iv) a maximum reflectance showed near $700 \mathrm{~nm}$; its magnitude and position were highly dependent on chlorophyll concentration. Highspectral-resolution data were used as a guideline for selection of the most suitable spectral bands for chlorophyll remote sensing. Models were devised, based on the calculation of the integrated area above the baseline from 670 to $850 \mathrm{~nm}$ and the reflectance maximal height within this range. Some algorithms already used in previous studies were tested and showed a plausible degree of accuracy when applied to the current data base. However, novel models devised in this study improved substantially the accuracy of Chl estimation by remotely sensed data, by reducing the estimation error from $>11$ to $6.5 \mathrm{mg} \mathrm{m}^{-3}$. Those models were validated by an independent data set where Chl concentration ranged over two orders of magnitude. The use of three relatively narrow spectral bands was sufficient for Chl mapping in Lake Kinneret. Therefore, a relatively simple sensor, measuring only a few bands will be employed in future applications for $\mathrm{Chl}$ monitoring in inland waters. Radiometric data were also used to simulate radiances in the channels of TM Landsat and to find the algorithm for Chl assessment. The ratio of channel 4 to channel 3 was used and enabled Chl estimation with an error of $<15 \mathrm{mg} \mathrm{m}^{-3}$. This algorithm was employed to map $\mathrm{Chl}$ in the entire area of Lake Kinneret with 10 gradations.
\end{abstract}

\section{Introduction}

The most conspicuous biological feature of Lake Kinneret is the periodic bloom of the dinoflagellate Peridinium gatunense Nygaard (Serruya, 1978; Pollingher, 1986), which displays a visual spatial discontinuous dispersion. The population of Peridinium increases with the onset of lake water mixing, and from February throughout May forms a dense crop. At the peak of the Peridinium bloom, from a practical view point the lake becomes a 'unialgal culture'. Therefore, any general technique applied for the determination of algal density, e.g. chlorophyll (Chl) concentration, actually measures Peridinium density. The horizontal distribution of Peridinium is highly irregular and patches of Peridinium are usually found (Berman and Rodhe, 1971; Pollingher and Berman, 1975). Fluorometric measurement of Chl in vivo (Berman and Rodhe, 1971; Berman, 1972) performed during the 
Peridinium bloom, as well as determination of extracted chlorophyll (Berman and Ellias, 1973), revealed the patchy spatial distribution of Peridinium in Lake Kinneret. Those studies confirmed previous results based on microscopic observations (Pollingher and Kimor, 1970).

The Peridinium patches are of an ephemeral nature, as are most other spatial heterogeneities in aquatic environments. However, the differences between the algal concentration within the patch and beyond its limits are higher than in most other systems. Therefore, any attempt at 'representative' sampling of the lake phytoplankton is a frustrating exercise.

Remote sensing could be an effective method for monitoring the distribution of algae in lake Kinneret. This would provide a synoptic view of the investigated area. Often, only a small number of images can highlight the best sampling locations and aid in the design or improvement of point sampling programs.

Remote sensing studies typically involve the mapping of concentrations of a given variable in water bodies using radiance collected by a sensor placed above the water surface. Quantification of concentrations is usually achieved by the development of empirical or semi-empirical models correlating the radiance (or reflectance), as measured by remote sensor, with the 'ground truth' data.

The spectral area used for remote sensing in Case I waters is limited to the blue and green range (Gordon and Morel, 1983). Attempts to apply Case I-derived algorithms for Case II productive waters have demonstrated their limitation when applied to measurements of waters with high concentrations of $\mathrm{Chl}$ and/or suspended and dissolved organic matter (GKSS, 1986).

In several cases, the fluorescence line height has been used successfully for the remote detection of Chl in Case II waters (e.g. Neville and Gower, 1977; Gower, 1980; Doerffer, 1981; GKSS, 1986; Fischer and Kronfeld, 1990). Quantitative accuracy is limited by the varying fluorescent efficiency of different phytoplankton populations and by changes in water absorption that reduce the light available for fluorescence. Although this technique seems to be useful for Chl detection, it is difficult to generalize and make comparisons based on previous studies, especially for inland waters with highly variable bio-optical properties.

The spectral features of reflectance of productive waters were studied in ecosystems with $\mathrm{Chl}$ concentrations ranging from 5 to $100 \mathrm{mg} \mathrm{m}^{-3}$ (e.g. in inland waters: Gitelson et al., 1986, 1993a,b; Dekker et al., 1992; Quibell, 1992; Dekker, 1993; in artificial ponds: Matthews and Boxall, 1994; Rundquist et al., 1995a,b). It was found that the position and the magnitude of the peak of reflectance near $700 \mathrm{~nm}$ strongly depended on Chl concentration (Gitelson et al., 1986; Vos et al., 1986; Gitelson, 1992, 1993b; Matthews and Boxall, 1994; Rundquist et al., 1995). This peak represents increased light scattering by algal cells in a region where $\mathrm{Chl}$ absorption declines (at wavelengths near $700 \mathrm{~nm}$ ) and water absorption increases. Different algorithms based on the properties of the peak near $700 \mathrm{~nm}$ were developed. They included: (i) its ratio to the reflectance at $670 \mathrm{~nm}$ (Gitelson et al., 1986, 1993a,b; Dekker, 1993; Han et al., 1995; Rundquist et al., 1995a); (ii) the position of this peak (Gitelson, 1992,1993; Rundquist et al., 1995a); (iii) calculation of the first derivative of reflectance (Rundquist et al., 1995b). 
The information available so far suggests that the spectral range from green to near IR should be utilized for constructing algorithms for remote Chl assessment.

Although methods for the quantitative estimation of Chl concentration were established and tested in several case studies (e.g. Gitelson et al., 1986, 1993a,b, 1994a,b; Dekker, 1993; Rundquist et al., 1995a), both qualitative and quantitative interpretation of the data are still incomplete. The optical properties of each 'optically active' constituent (phytoplankton, detritus material, non-organic suspended matter as well as dissolved organic matter) are complex and variable, and their influence on reflectance spectra is still not fully understood.

The first objective of our study was to devise optical models of the lake, relating the reflectance obtained just above the water surface to Chl concentration in the surface water. This was done by the selection of spectral bands that displayed maximal and minimal sensitivity to variation in Chl concentration. Several algorithms were developed to assess Chl concentration, utilizing just a few spectral bands as the first step to employ remote sensing technology in the monitoring of phytoplankton distribution in Lake Kinneret.

The second objective was to use the Landsat Thematic Mapper (TM) data for large-scale monitoring of Lake Kinneret water quality. In order to achieve this goal, high-resolution radiometric data were used to simulate the radiances in different channels of the TM. Then algorithms for the retrieval of Chl concentration from TM images were devised. The TM data were processed using the algorithm and the derived $\mathrm{Chl}$ concentrations were compared to in situ observations.

\section{Method}

Two experiments were carried out in 1993 in Lake Kinneret during the Peridinium bloom from 23 to 25 March and from 28 to 29 April. Forty and 37 stations were sampled in March and April, respectively. The sampling scheme was devised to cover as high a variation of $\mathrm{Chl}$ and suspended matter (SM) concentrations as possible in each experiment.

At every sampling station, the upwelling radiance of water, $L_{\mathrm{w}}$, and (indirectly) the downwelling radiance, $L_{0}$ (with the aid of a standard reference $\mathrm{BaSO}_{4}$ plate), were measured by a portable LICOR LI- 1800 radiometer in the range from 400 to $850 \mathrm{~nm}$ with a spectral resolution of $2 \mathrm{~nm}$. In March 1993, during Landsat overpass, the spectral range was expanded to $1100 \mathrm{~nm}$ to simulate the corresponding channel of the satellite sensor. The radiometer was attached to a telescope with a field of view of $15^{\circ}$, which was positioned over the water at a height of $2 \mathrm{~m}$. The $15^{\circ}$ optic resulted in an instantaneous field of view of $\sim 50 \times 50 \mathrm{~cm}$ on the water surface. A microcomputer initiated spectroradiometer scanning and stored the data.

The upwelling radiance of the water, $L_{\mathrm{w}}$, was measured at least three times. The mean value was used in the analysis. One spectrum was measured for $\sim 25 \mathrm{~s}$; therefore, one set of reflectance measurements took $<2 \mathrm{~min}$. Each observed upwelling radiance spectrum of the water was divided by the appropriate upwelling radiance spectrum of the reference plate, giving the reflectance as $R=L_{\mathrm{w}} / L_{0}$.

To minimize the contribution of specular reflected radiance during clear-sky conditions, the telescope was directed towards the water surface at an angle of 
$\sim 20^{\circ}$ off the nadir, and opposite to the direction of the sun's azimuth, where specular reflectance is at a minimum.

Water was sampled with a 51 Aberg-Rodhe sampler, $0.0-0.5 \mathrm{~m}$ below the surface. Two $100 \mathrm{ml}$ subsamples were immediately filtered and stored on ice in $5 \mathrm{ml}$ $90 \%$ acetone. Upon return to the laboratory, $5 \mathrm{ml}$ of $90 \%$ acetone were added to the filters and each sample was sonicated for $1 \mathrm{~min}$, and left in the dark overnight at $4^{\circ} \mathrm{C}$. The extract was subsequently cleared by centrifugation and measured fluorometrically to determine the Chl concentration (Holm-Hansen et al., 1965).

The Landsat TM image was acquired simultaneously with March measurements taken on the lake when the sky was completely clear and cloud free. The Landsat TM image underwent a geometrical correction process so we could locate the sampling stations and extract radiometric data for validation. As the result of this process, every pixel in the image corresponded to a known location in th study area and the radiometric data for each location were examined. A $3 \times 3$ pixel window $(90 \times 90 \mathrm{~m})$, centered on the sample point, was used to extract readings for each of the multispectral bands. These data were then averaged for each sample point to reduce sensor noise (Ritchie and Cooper, 1987).

Atmospheric correction was carried out by an algorithm developed by Fraser $e t$ al. (1992). Input data for the correction consisted of the TM-measured radiances, view and illumination directions, and aerosol optical thickness derived from ground-measured values of solar transmission (Kaufman and Fraser, 1983). The output data produced were the surface reflectances for corresponding points in the image.

The measurements of transmission of the direct sunlight were performed with a sun photometer with eight spectral channels between 400 and $1030 \mathrm{~nm}$ (Kaufman, 1993). Measurements were taken when local sources of atmospheric pollution were not evident. Therefore, we can assume that the atmosphere was spatially homogeneous across the lowest 2-4 km of atmosphere where most of the tropospheric aerosol is present. The optical thickness was measured with an error of \pm 0.01 to \pm 0.02 (Kaufman, 1993).

The developed algorithm and atmospherically corrected image data were used to produce a Chl concentration map of Lake Kinneret. Several horizontal stripes were present in the image over the total water area. This made interpretation difficult. This noise is produced by non-conformity of the 16 detectors that scan the area across the path of the satellite movement. To eliminate this noise, a twodimensional Fourier transform filtering method was used. The filter was applied to 'water' pixels only, masked by using radiance data from the IR channel TM4, to distinguish between land and water. An additional averaging (low-pass) filter was applied to remove random high-frequency noise (a despeckling filter). The filtered lake image was converted from gray levels into shades of blue-cyan and planted in the surrounding land image using the land-sea mask.

\section{Results}

The phytoplankton assemblage was dominated by P.gatunense in both experiments. Chlorophyll concentrations ranged from 5.1 to $185 \mathrm{mg} \mathrm{m}^{-3}$ in March and 
from 2.4 to $187.5 \mathrm{mg} \mathrm{m}^{-3}$ in April. The nanoplanktonic component was $>10 \%$ only in samples with $\mathrm{Chl}$ concentrations $>10 \mathrm{mg} \mathrm{m}^{-3}$.

\section{Reflectance spectra}

Representative reflectance spectra are presented in Figure 1. For Chl concentrations $>20 \mathrm{mg} \mathrm{m}^{-3}$, a minimum is seen in the blue range of the spectrum. Reflectance increased in this range with the decrease in $\mathrm{Chl}$ concentration. This tendency was more obvious in the domain of $480-520 \mathrm{~nm}$ than at the shorter wavelengths. For Chl concentrations $>20 \mathrm{mg} \mathrm{m}^{-3}$, the reflectance was extremely low, only $1 \%$ at its highest.

The reflectance peaked between 550 and $580 \mathrm{~nm}$. The peak width and its magnitude decreased with the increase in Chl concentration. In samples with the highest $\mathrm{Chl}$ concentration, reflectance did not exceed $3 \%$ due to strong absorption by phytoplankton pigments even at these wavelengths. In the range from 590 to $650 \mathrm{~nm}$, the reflectance spectra of all the samples with a Chl concentration of $>10 \mathrm{mg} \mathrm{m}^{-3}$ were practically uniform.

A reflectance minimum was found at $670 \mathrm{~nm}$. It was $\sim 1 \%$ and was virtually non-dependent upon $\mathrm{Chl}$ concentration, which covered a wide range from 10 to $>180 \mathrm{mg} \mathrm{m}^{-3}$. In samples with low $\mathrm{Chl}$ concentration, e.g. $5 \mathrm{mg} \mathrm{m}^{-3}$, a small peak was found at $683 \mathrm{~nm}$, corresponding to phytoplankton fluorescence. This peak was consistently found in Lake Kinneret during a low Chl period (Gitelson et al., 1994b).

A red maximum appeared near $700 \mathrm{~nm}$ (Figure 1). The first derivative of the reflectance demonstrated the shift of null values from 680 (for $\mathrm{Chl}=5 \mathrm{mg} \mathrm{m}^{-3}$ ) up to 712 (for $\mathrm{Chl}=185 \mathrm{mg} \mathrm{m}^{-3}$ ). This demonstrates a shift in the reflectance maximum toward longer wavelengths with an increase in Chl concentration.

\section{Chlorophyll detection using high-spectral-resolution data}

The index for $\mathrm{Chl}$ estimation should depend solely on $\mathrm{Chl}$ and no other water constituents, and should not be influenced by survey conditions. Therefore, the wavelength at which only one dominant factor will influence spectral feature variation (beside pure water) will be the most useful for the determination of constituent concentration. Reflectance spectra obtained during the Peridinium period showed that the red reflectance maximum, near $700 \mathrm{~nm}$, is the only feature meeting the above criteria. The position of the peak, as well as its magnitude, were closely related to $\mathrm{Chl}$ concentration (Figure 1). The SD of reflectance values throughout the entire range from 400 to $850 \mathrm{~nm}$, as well as the coefficient of variation, showed that the sensitivity to Chl variation in the range near $700 \mathrm{~nm}$ was 2- to 3 -fold higher than in the blue region of the spectrum (Figure 2).

One must also include in the Chl determination index the reflectance at the spectral bands with the minimal sensitivity to variation in Chl concentration. The impact of all other water constituents, excluding Chl, should be uniform for both (maximal and minimal sensitivity to $\mathrm{Chl}$ concentration) reflectances. This spectral band was found near $670 \mathrm{~nm}$ (Figures 1 and 2).

The index $R_{\max } / R_{670}$ was constructed. $R_{\max }$ is the reflectance at a wavelength corresponding to peak height near $700 \mathrm{~nm}$. The index was compared with $\mathrm{Chl}$ 


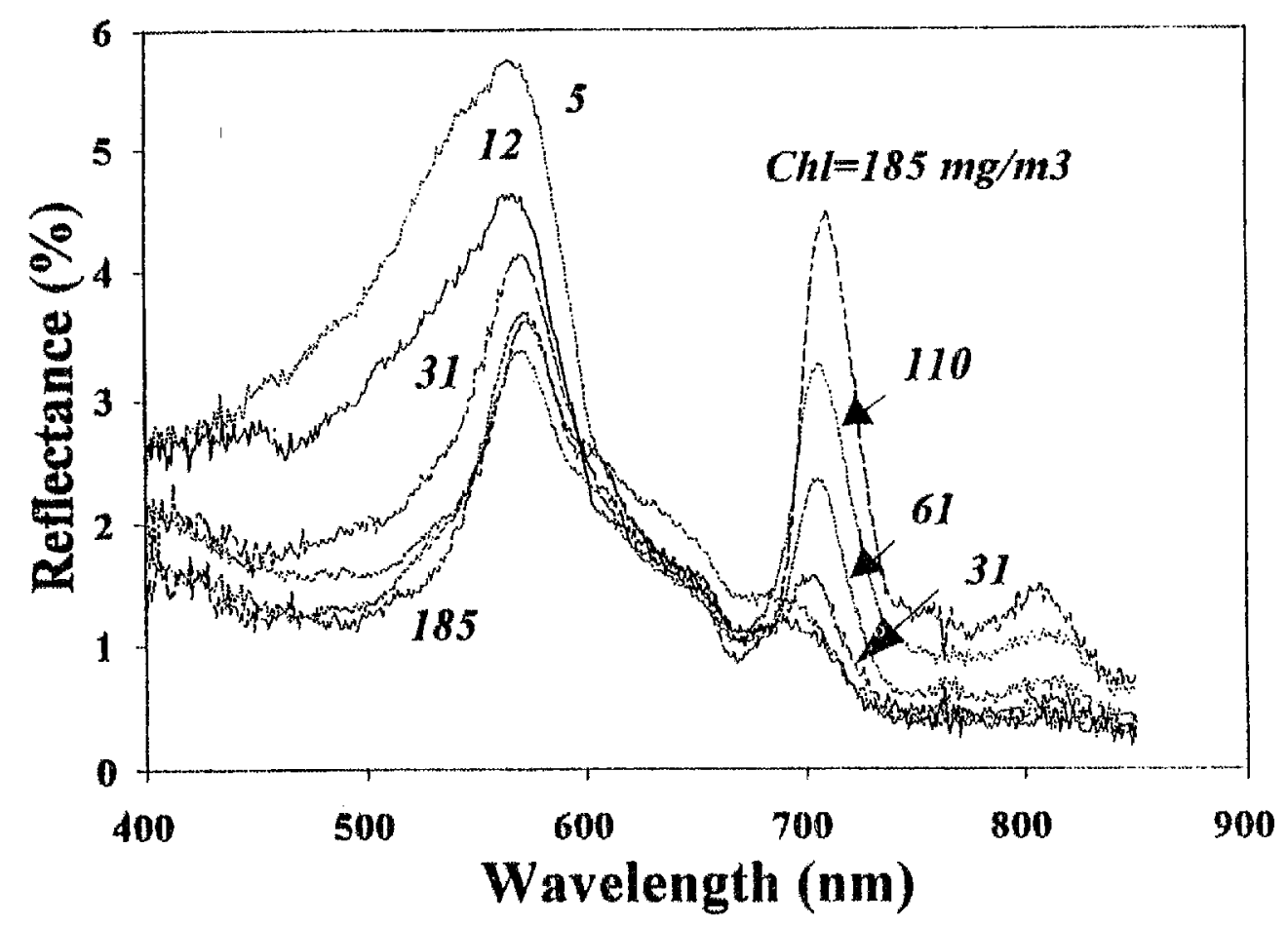

Fig. 1. Reflectance spectra recorded in Lake Kinneret in March 1993. The numbers indicate measured Chl concentrations.

concentration as measured in situ (Figure 3a). Linear regressions were computed as follows.

For the March set:

$$
\mathrm{Chl}=-32.35+(43.08 \pm 1.60) \times R_{\text {max }} / R_{670}
$$

$r^{2}=0.95, n=41$, with an estimation error of Chl of $11.53 \mathrm{mg} \mathrm{m}^{-3}$.

For the April set:

$$
\mathrm{Chl}=-40.04+(48.00 \pm 1.62) \times R_{\max } / R_{670}
$$

$r^{2}=0.96, n=37$, with an estimation error of Chl of $10.9 \mathrm{mg} \mathrm{m}^{-3}$.

The model was validated by an independent data set. We carried out this validation by applying equation (1) (derived from the March set) to calculate Chl concentration by using reflectance measurements that were obtained in April. The resulting predicted values were compared to the in situ $\mathrm{Chl}$ values measured in April (Figure 4a). The correlation between predicted and measured sets was $r^{2}=$ 0.96 , and the linear regression was

$$
C h l_{\text {pred }}=5.14+0.86 C h l_{\text {meas }}
$$

with an estimation error for $\mathrm{Chl}$ concentration of $<9.55 \mathrm{mg} \mathrm{m}^{-3}$.

The underestimation of the predicted values in comparison with measured quantities derives from our experimental inability to sample both the water parcel and the spectra simultaneously. This point is very important for waters with high 


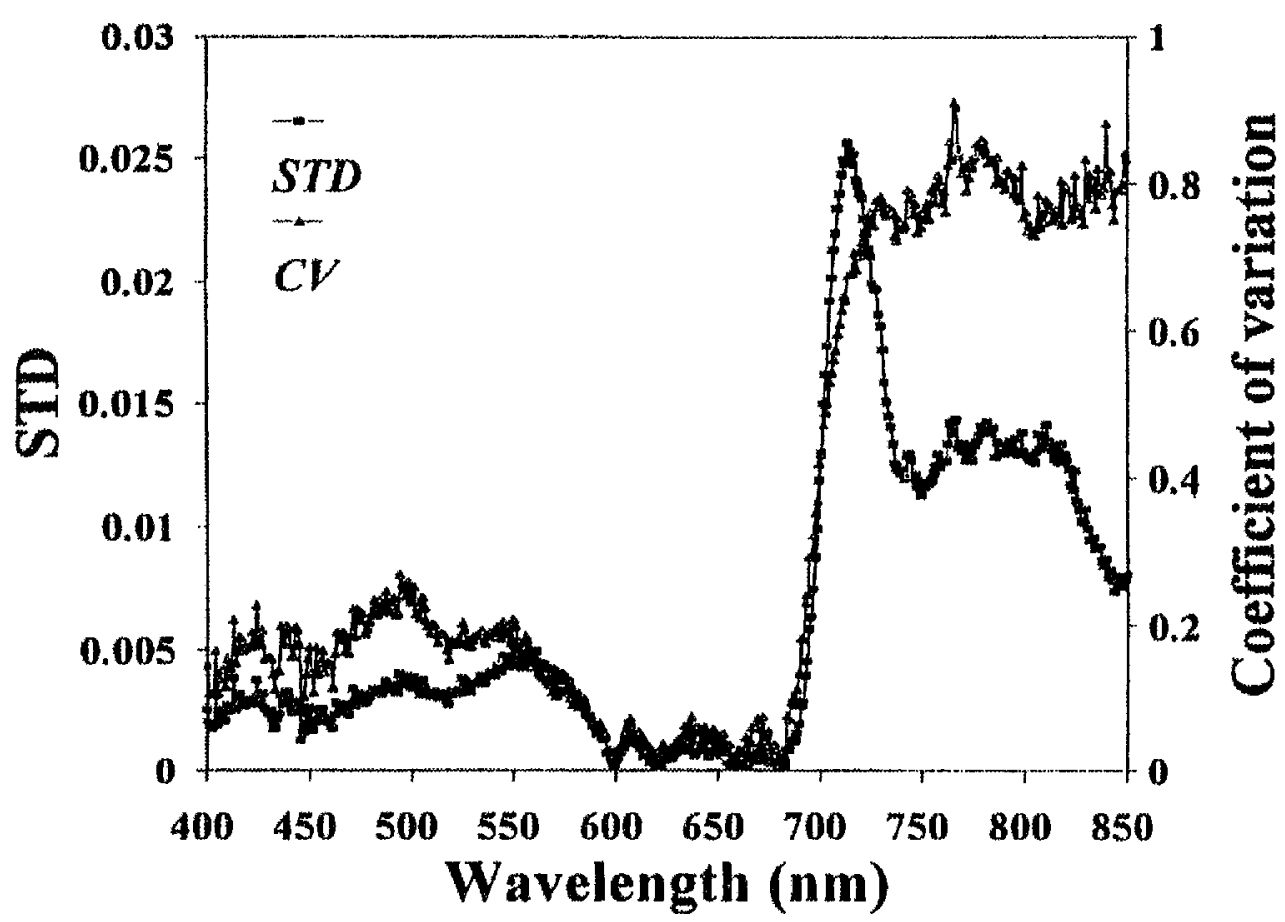

Fig. 2. Spectra of standard deviation (SD) of reflectance and coefficient of variation (ratio of SD to mean reflectance) for the March 1993 data set (40 sampling stations).

spatial and temporal variability of the distribution of suspendoids (see Discussion).

Two new methods of Chl estimation were developed in this study. One of them used the reflectance height at the wavelength corresponding to peak maximum above the baseline, spanned between 670 and $850 \mathrm{~nm}$. The reflectance in this range of the spectrum depends almost entirely on Chl absorption and scattering by phytoplankton (Dekker, 1993; Gitelson, 1992, 1993; Quibell, 1992). The $850 \mathrm{~nm}$ point was selected because it is a wavelength at which the variation of reflectance was minimal.

By using the $670-850 \mathrm{~nm}$ baseline, we could calculate the reflectance line height (RLH) and compare it to Chl concentration for the two data sets (Figure 3b). The relationship for the March set was:

$$
\mathrm{Chl}=1.77+(40.77 \pm 1.76) \times R L H_{660-850}
$$

$r^{2}=0.96, n=41$, with an error of $10.5 \mathrm{mg} \mathrm{m}^{-3}$; and for the April data set:

$$
\mathrm{Chl}=2.27+(43.42 \pm 0.95) \times R L H_{670-850}
$$

$r^{2}=0.98, n=37$, with an estimation error of $\mathrm{Chl}$ of $<6.71 \mathrm{mg} \mathrm{m}^{-3}$.

Equation (4) was validated, by using the April data set (Figure 4b), with the following result:

$$
\mathrm{Ch}_{\text {pred }}=1.07+0.91 \mathrm{Ch}_{\text {meas }}
$$

with $r^{2}=0.98$ and an estimation error of chlorophyll of $<6.18 \mathrm{mg} \mathrm{m}^{-3}$.

The second method for $\mathrm{Chl}$ estimation used the sum of reflectance above the baseline from 670 through $850 \mathrm{~nm}$ as a $\mathrm{Chl}$ indicator. The estimation errors of those 

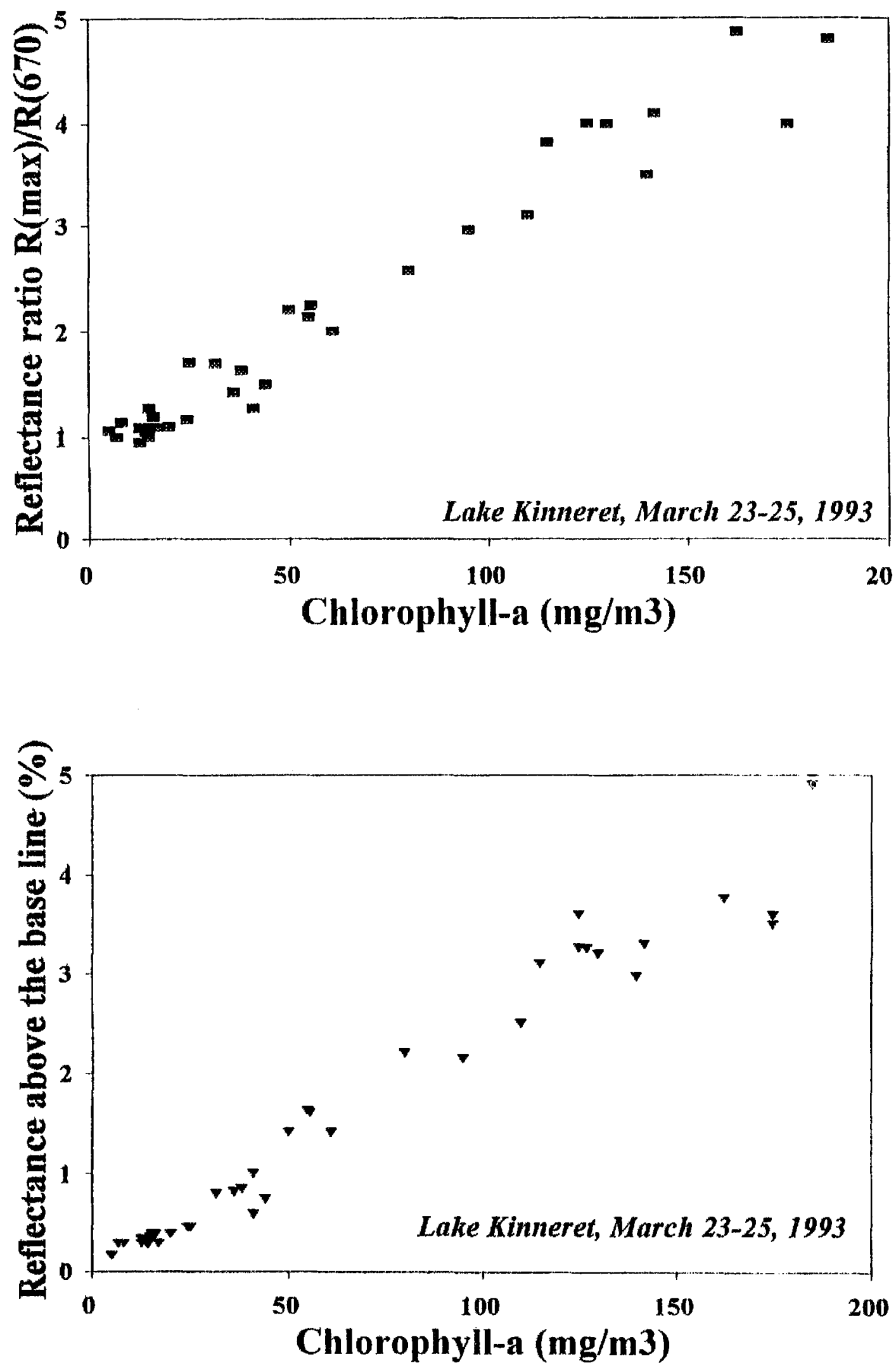

Fig. 3. Pairwise comparison of optical variables plotted against Chl concentration. (a) The ratio of maximal reflectance in the red range $\left(R_{\max }\right)$ to the reflectance at $670 \mathrm{~nm}\left(R_{670}\right)$. (b) The reflectance line height $\left(R L H_{670-850}\right)$ above the baseline from 670 to $850 \mathrm{~nm}$. 
algorithms were found to be of the same order of magnitude as those found from equation (4).

The developed algorithms avoided, to a certain degree, the problems of variation in peak position and its shape. Both accounted not only for height of the peak near $700 \mathrm{~nm}$, but also for the $\mathrm{Chl}$ absorption at $670 \mathrm{~nm}$, and enhanced the accuracy of estimations. Variability in the amount of suspended matter caused changes in the slope of reflectance spectra from 600 to $850 \mathrm{~nm}$. This tilted the baseline, but did not prevent accurate determination of the line height and sum of reflectance above the baseline (Gitelson et al., 1994b).

\section{Chlorophyll detection using Landsat Thematic Mapper}

The option of using Landsat TM images for the estimation of Chl distribution in Lake Kinneret was investigated by simulation of radiance in the channels of TM by the measured reflectance spectra. The variation of simulated radiance in the third channel TM3 $(600-690 \mathrm{~nm})$ was minimal. This indicated that scattering by particles and absorbance by pigments were almost in equilibrium in this range of the spectrum. Maximal variation of simulated reflectances was found in channel TM4 $(800-1100 \mathrm{~nm})$. These findings suggest that $\mathrm{Chl}$ assessment may be feasible using an index constructed as a ratio of TM4/TM3. This ratio should be maximally sensitive to Chl concentration and, to a certain degree, invariant with respect to survey conditions.

Figure 5 demonstrates the comparison of the developed index (as a ratio of simulated radiances TM4/TM3) with the actual measured Chl concentration. The correlation coefficient $\left(r^{2}\right)$ for a linear relationship was found to be 0.92 .

The findings were examined using reflectances extracted from atmospherically corrected TM data. The correlation between TM-derived Chl and measured Chl concentration was $r^{2}=0.79$. The estimation error for Chl was $<15.8 \mathrm{mg} \mathrm{m}^{-3}$. This allowed mapping of $\mathrm{Ch}$ l ranging from 5 to $185 \mathrm{mg} \mathrm{m}^{-3}$, with 10 gradations (Figure 6). In this false color map, the patchy nature of the phytoplankton spatial distribution is well displayed. The decrease in the accuracy of Chl estimation using TM data was probably caused by very high temporal variation in Chl distribution during our measurements. As a consequence, this hampered our ability to compare accurately remotely sensed data and ground data.

\section{Discussion}

\section{Optical properties}

The reflectance near $550 \mathrm{~nm}$ did not follow the conceptual model of algal reflectance (Gordon and Morel, 1983). In our experiments, we found a negative correlation between algal concentration and the reflectance in the green range of the spectrum (as well as between the simulated radiance in TM2 and algal concentration). Absorption by carotenoids is apparently the reason for this spectral feature. During the Peridinium bloom period, peridinin and diadinoxanthin are the most abundant carotenoids (Dubinsky and Polna, 1976). Peridinin absorbs in vivo up to $570 \mathrm{~nm}$ (Bidigare et al.,1990) and therefore it reduces reflectance in the green range. Scattering by phytoplankon cells (as well as other organic and non-organic 

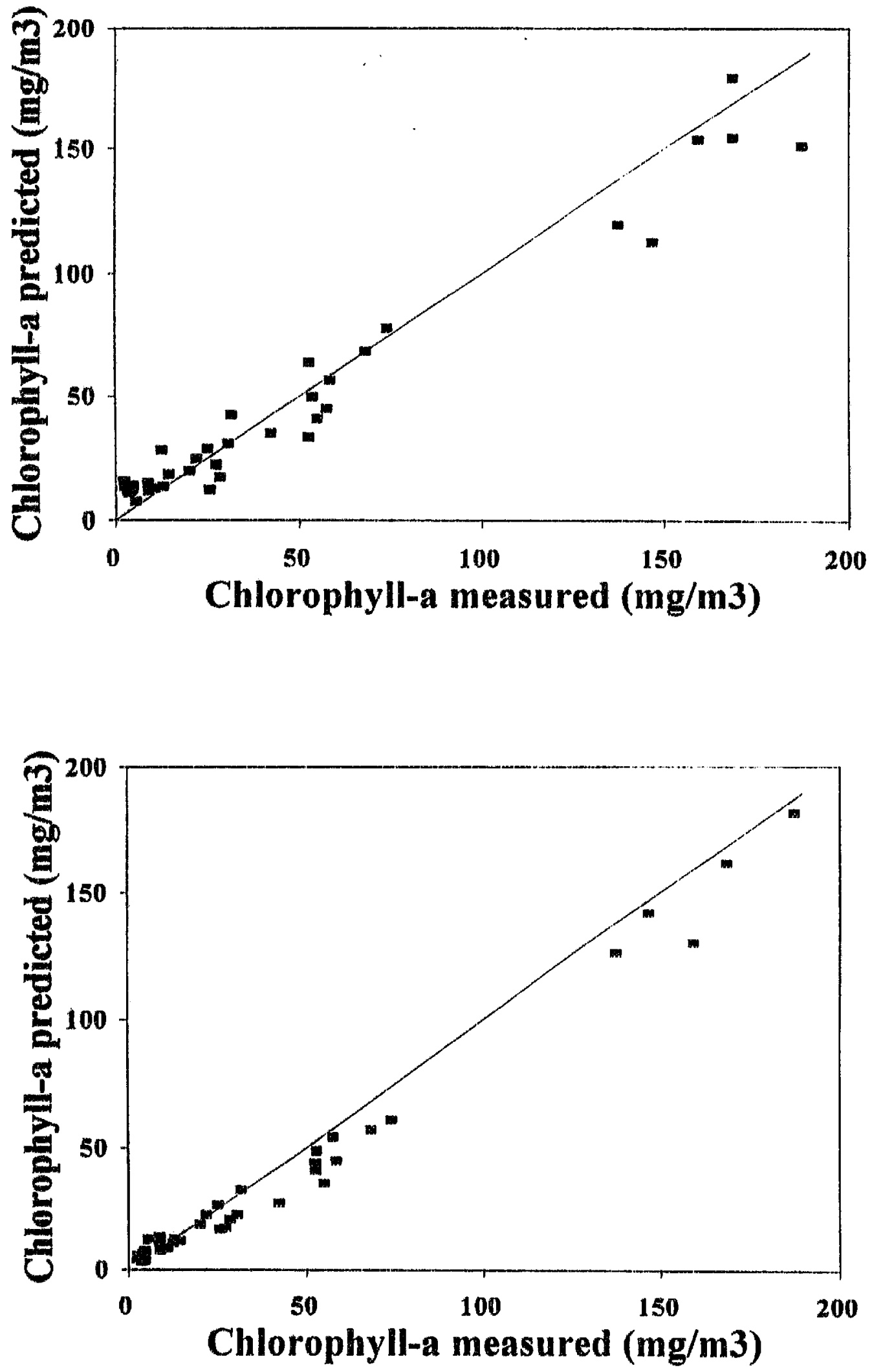

Fig. 4. Validation of the models presented in Figure 3 by data sets acquired in April. (a) Equation (3) $-R_{\max } / R_{670}$, (b) equation (6)-RLH $H_{670-830^{\circ}}$ 


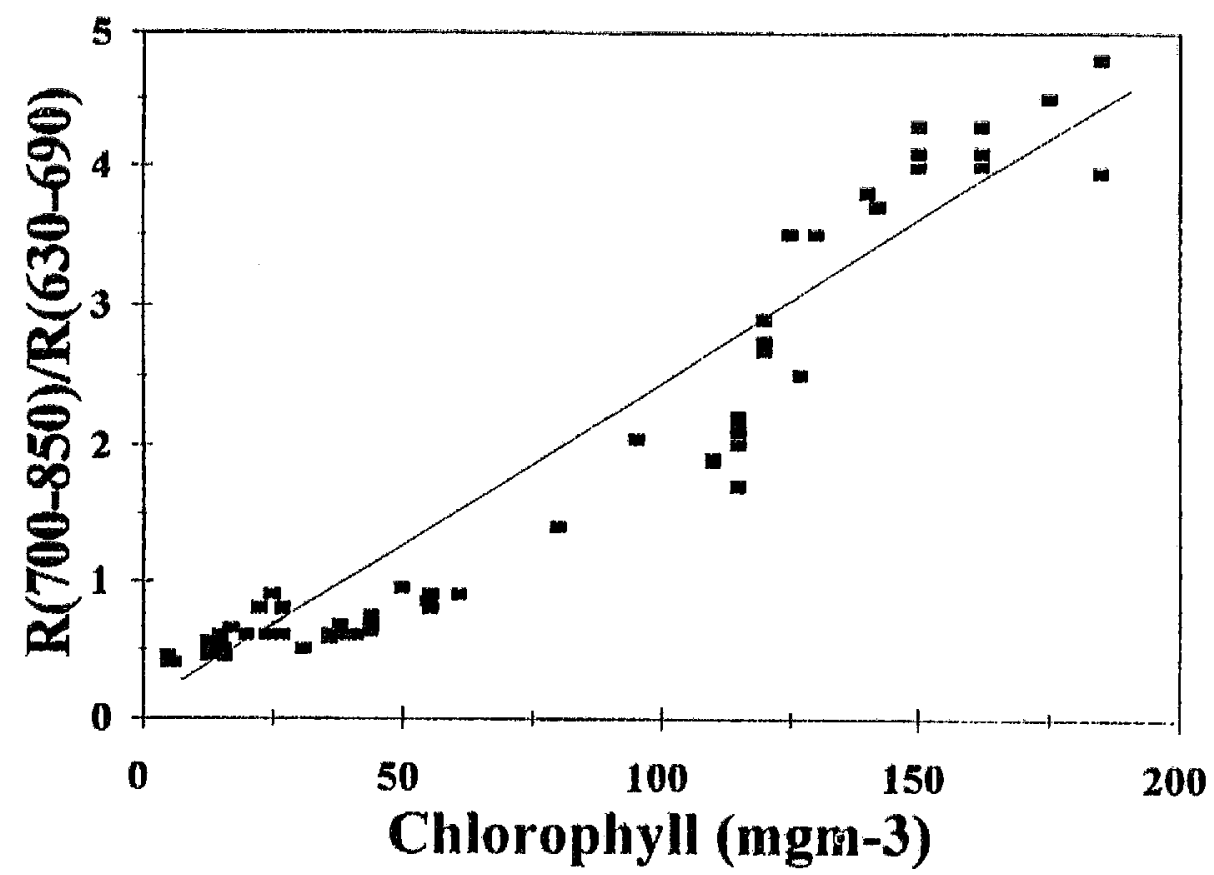

Fig. 5. Ratio of simulated radiances in the channels of Landsat TM versus measured chlorophyll concentrations.

particles) also affects the spectral behavior of reflectance. A decrease in reflectance when $\mathrm{Chl}$ increases confirms the finding that absorption is dominant over scattering in this spectral range. This is, apparently, a feature of Peridinium (and other chromatophytes) that distinguishes them from green and blue-green algae (e.g. Quibell, 1992; Dekker, 1993; Rundquist et al., 1995a). Absorption by peridinin, which in vivo peaks in the range from 490 to 510 , is the governing factor of reflectance in the green region. This can be explained by the enormous concentrations of Peridinium during the bloom period.

It was discovered recently that the reflectance at $670 \mathrm{~nm}$ remains almost constant over a wide range of Chl a concentrations (Gitelson et al., 1986, 1993a,b; Dekker, 1993; Rundquist et al., 1995a). When phytoplankton density increases, the reflectance near $670 \mathrm{~nm}$ should also increase, due to elevated scattering by phytoplankton cells. Concurrently, the increase in Chl $a$ absorption should lead to a decrease in reflectance. When the Chl concentration is $>10 \mathrm{mg} \mathrm{m}^{-3}$, the processes of absorption and scattering are almost in equilibrium, and phytoplankton density hardly affects the reflectance at $670 \mathrm{~nm}$ at all. Therefore, reflectance at $670 \mathrm{~nm}$ primarily depends on the concentrations of non-pigmented organic and nonorganic suspended matter.

A decrease in Chl absorption and an increase in pure water absorption result in a minimum of the combined absorption curve of algae and water near $700 \mathrm{~nm}$ (Vasilkov and Kopilevich, 1982; Gitelson et al., 1986; Vos et al., 1986; Gitelson, 1992, 1993). An increase in algal density leads to enhancement of scattering and, as a consequence, to increased reflectance, which shifts the peak position towards longer wavelengths. 


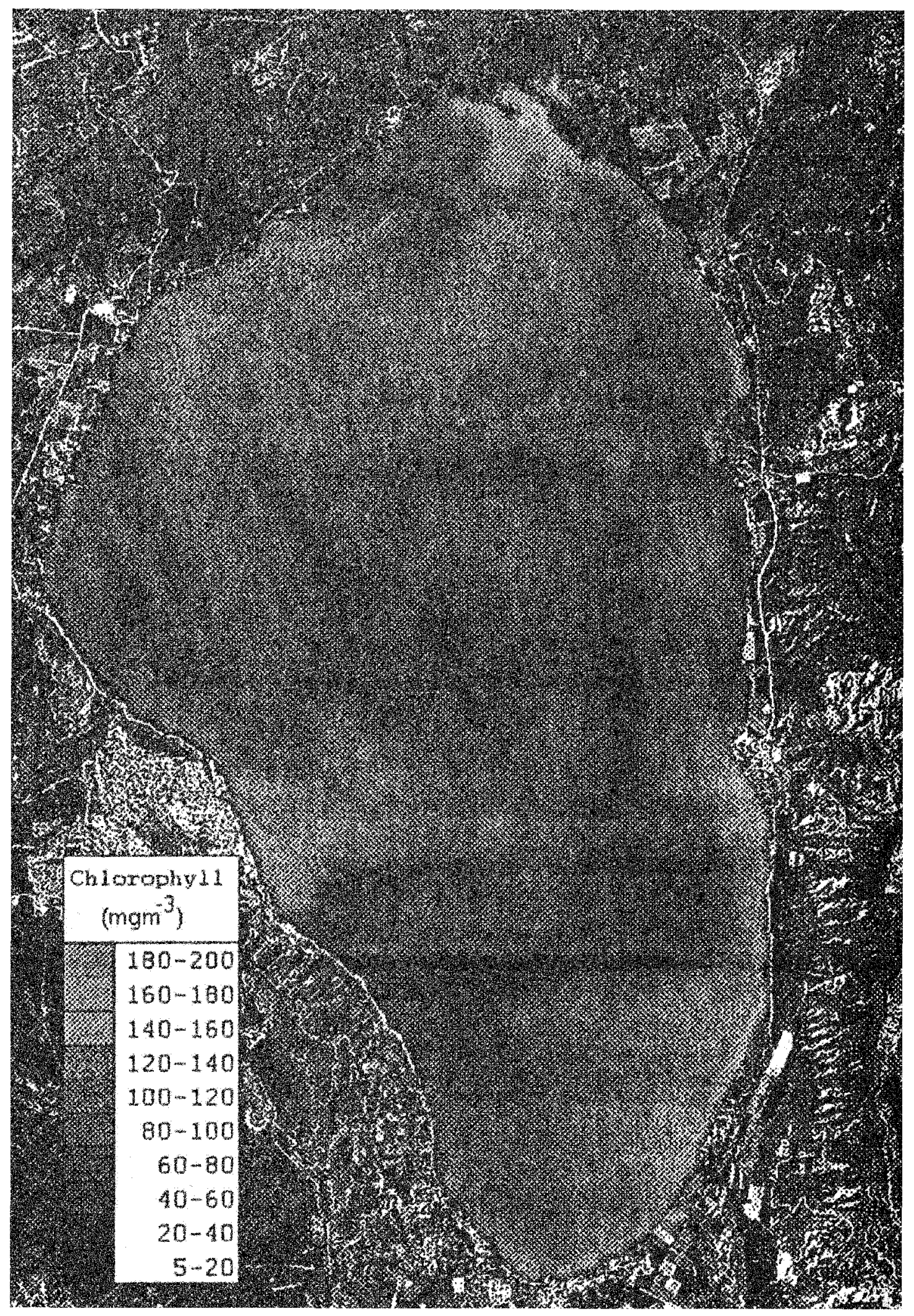

Fig. 6. False color map of phytoplankton distribution in Lake Kinneret, produced from the radiance ratio TM4/TM3. The Landsat TM image was acquired on 23 March, 1993. 
For Chl concentrations of $>20-30 \mathrm{mg} \mathrm{m}^{-3}$, scattering by phytoplankton cells is the dominant factor in the near-IR region of the spectrum, and governs the spectral behavior of reflectance. The same effects were found to be dominant for green and blue-green algae (Quibell, 1992; Rundquist et al., 1995a,b). On the other hand, these observations are significantly different from observations in productive coastal waters, where the region near $680 \mathrm{~nm}$ (natural fluorescence signal) was considered the most appropriate for gathering information on $\mathrm{Chl}$ concentration (GKSS, 1986; Fischer and Kronfeld, 1990).

\section{Spatial and temporal variation}

The stability of the proposed models depends on several factors. The main group of factors relates to the inherent optical properties of algal cells, non-organic and detrital particles. Therefore, the parameters to be used in the models pertain to the nature of suspended and dissolved water constituents. Change in taxonomic composition of the phytoplankton, the intrinsic organization of pigments within cells ('package effect'), the particle size distribution of non-living materials and the nature of dissolved matter will affect the reflected signal. From studies of the vertical attenuation coefficient of Lake Kinneret, we know that the underwater light field undergoes dramatic changes throughout the year (Dubinsky and Berman, 1979). It can be seen that the 'background' of the attenuation coefficient increases significantly with the increase in phytoplankton biomass density. We have also noted in our preliminary studies that the nature of the reflectance is variable throughout the year (Gitelson et al., 1994a). Some of the changes may be partly attributed to variations in the inherent optical properties of the water constituents, and partly to differential proportions between different components of the suspended matter. Thus, for example, the linear correlations between Chl and SM concentrations were $r^{2}=0.71$ and 0.68 , in March and April, respectively. These values are considerably higher than the $r^{2}=0.31$, which was found in Lake Kinneret during a low Chl period (Gitelson et al., 1994b).

Reflectance spectra acquired in a very limited area of Lake Kinneret during Peridinium bloom may be highly variable. The reflectance spectra presented in Figure 7 were collected at three sampling stations, spaced $\sim 10 \mathrm{~m}$ apart in a tiny sheltered bay. Yet, the measured chlorophyll concentrations were 46, 112 and 170 $\mathrm{mg} \mathrm{m}^{-3}$. This phenomenon is even more pronounced in the pelagic waters of the lake, and algal concentration variation can often be detected visually.

Another group of factors which influence the stability of the parameters used in the proposed algorithms relate to some technical limitations in our measurement method and equipment. During field data acquisition, we often found a 2-fold difference in Secchi depth measured on two sides of the boat spaced $2.5 \mathrm{~m}$ apart. Water motion induces further temporal variation of algal distribution, therefore several spectra collected at a given point within 2-3 min may be highly variable. In Figure 8, four spectra are presented and the difference between the extremes is $\sim 300 \%$. This finding is an indication that firm 'ground truth' can hardly be achieved from so temporally variable a source as Peridinium populations during the bloom of this alga. Consequently, we have to assume that our 'ground truth' is 


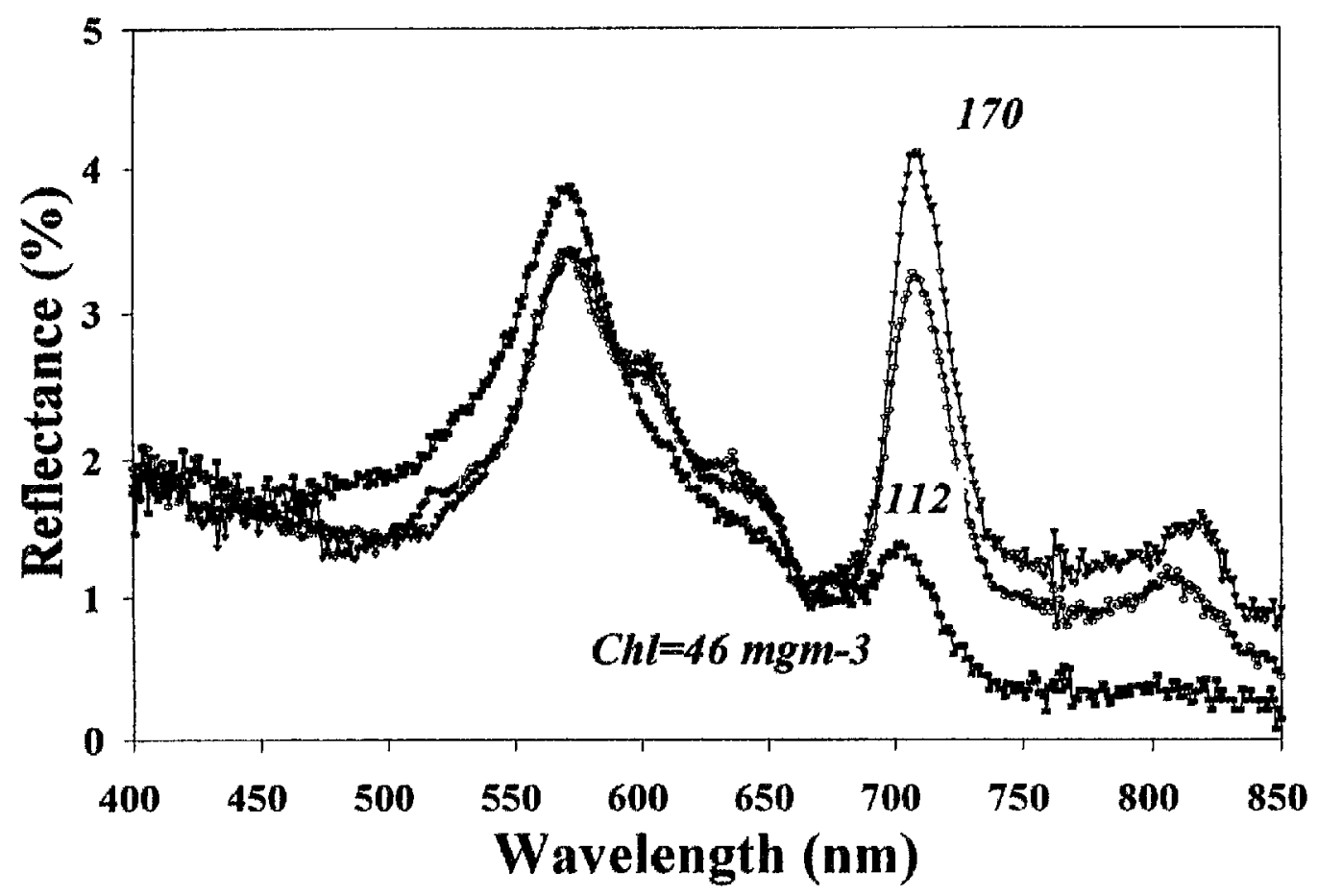

Fig. 7. Reflectance spectra recorded in Lake Kinneret in a sheltered offshore location. The numbers indicate measured Chl concentrations.

just an approximation of the sample which was spectrally measured rather than its concrete representative. The duration of the spectral measurement in our experiment was $25 \mathrm{~s}$. The technical drawback of time mismatch between the water sampling and spectral measurement could be diminished if the latter were collected by a faster instrument.

\section{Limnological considerations}

A major issue of remote sensing of algae is the question of the correlation of the radiance emitted from the water surface, i.e. the concentration of algae at the surface, and the vertical distribution of algae throughout the entire water column. The vertical movement of Peridinium throughout the diel cycle was studied in Lake Kinneret (Pollingher, 1988). It was found that Peridinium migrated upward from the early morning until the afternoon, and then sank downward from late afternoon until midnight. Strong winds suppressed the upward vertical movement and induced aggregation of Peridinium cells on top of the thermocline. Dinoflagellates are capable of directional movement, and vertical migration was assumed as an optimization mechanism, that enables the algae to occupy a suitable niche at any given period of time (George and Heaney, 1978; Heaney and Talling, 1980). Light requirements, nutrient availability and the cellular concentration of heavy photosynthesates are presumably the factors driving dinoflagellate vertical movements (Talling, 1971; Heaney and Epply, 1981). 


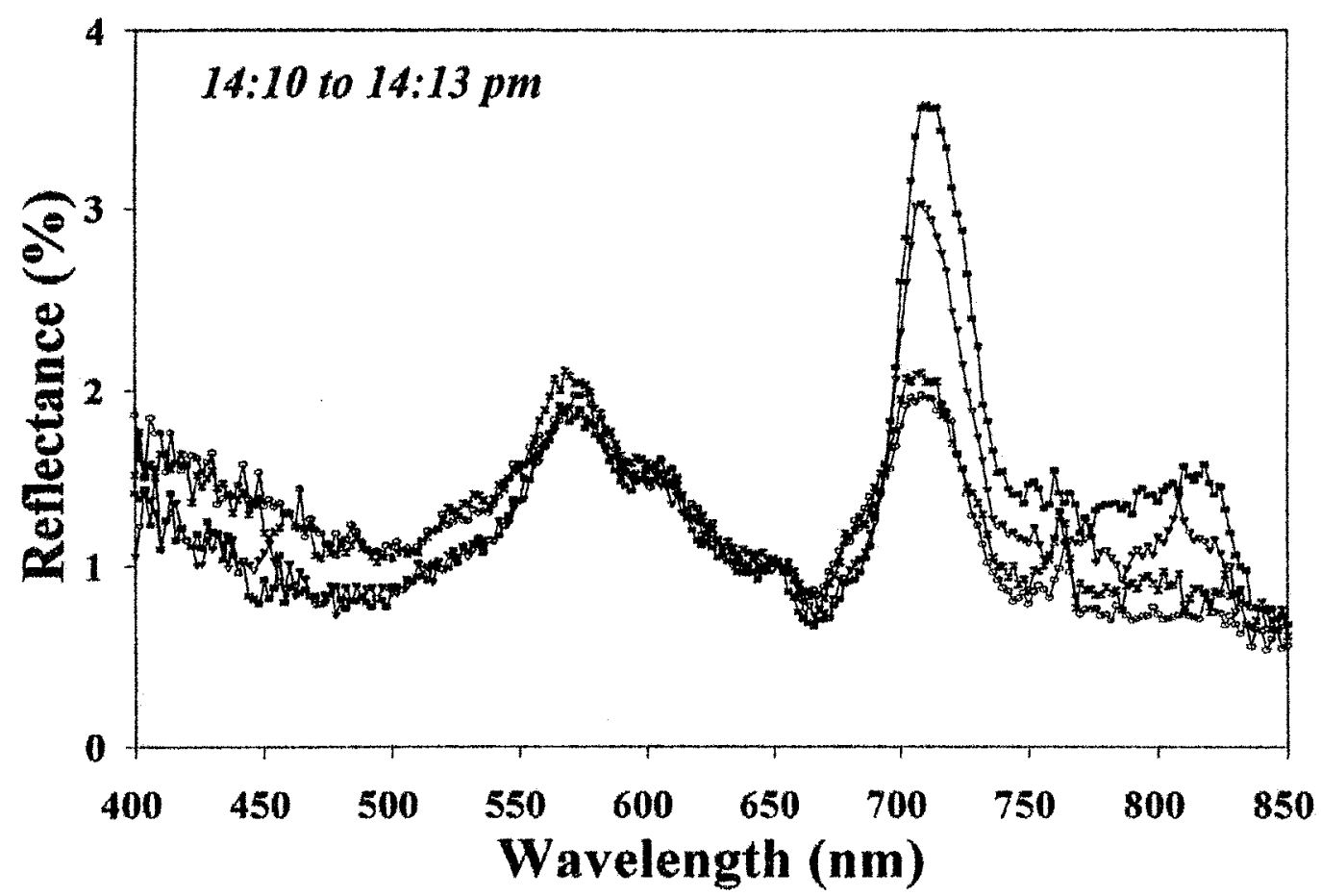

Fig. 8. Reflectance spectra recorded in Lake Kinneret within $3 \mathrm{~min}$ in a pelagic station.

It is obvious that the relationship between cell concentration at the surface and cell concentration in the entire water column is subject to wide seasonal and diurnal variation (Berman and Rodhe, 1971; Pollingher and Berman, 1975; Pollingher, 1988). Remote sensing of Lake Kinneret during Peridinium bloom is, therefore, limited as a tool for phytoplankton biomass estimation. However, if the relationship between the surface cell concentration and the total concentration of the algae varies within a relatively narrow range, remote sensing may be used for monitoring the spatial distribution of Peridinium. A series of measurements showed that the mode of vertical alignment was quite consistent when several stations were sampled within a short time span (Berman and Rodhe,1971). We found that the concentration of Peridinium observed at the surface correlated plausibly with the integrated concentration of this alga in the upper $10 \mathrm{~m}$ water column when checked at 26 stations within $5 \mathrm{~h}$ (Figure 9). Although much effort is still required to evaluate the above-mentioned relationship, we assume that the patchiness of Peridinium observed at the surface is due to a three-dimensional structure and is not the result of differential vertical distribution. Therefore, sampling of vertical profiles at several stations should be used as a supplement to remote sensing for the assessment of algal biomass during Peridinium bloom in Lake Kinneret.

\section{Satellite-carried sensors}

It should be noted that the optical sensors carried by existing spacecraft are not specifically designed to monitor water color. The sensor bands are too wide to be able to detect features as specific as those that were revealed in our study. Yet, the results of the current TM analysis of Lake Kinneret (as well as during a low $\mathrm{Chl}$ 


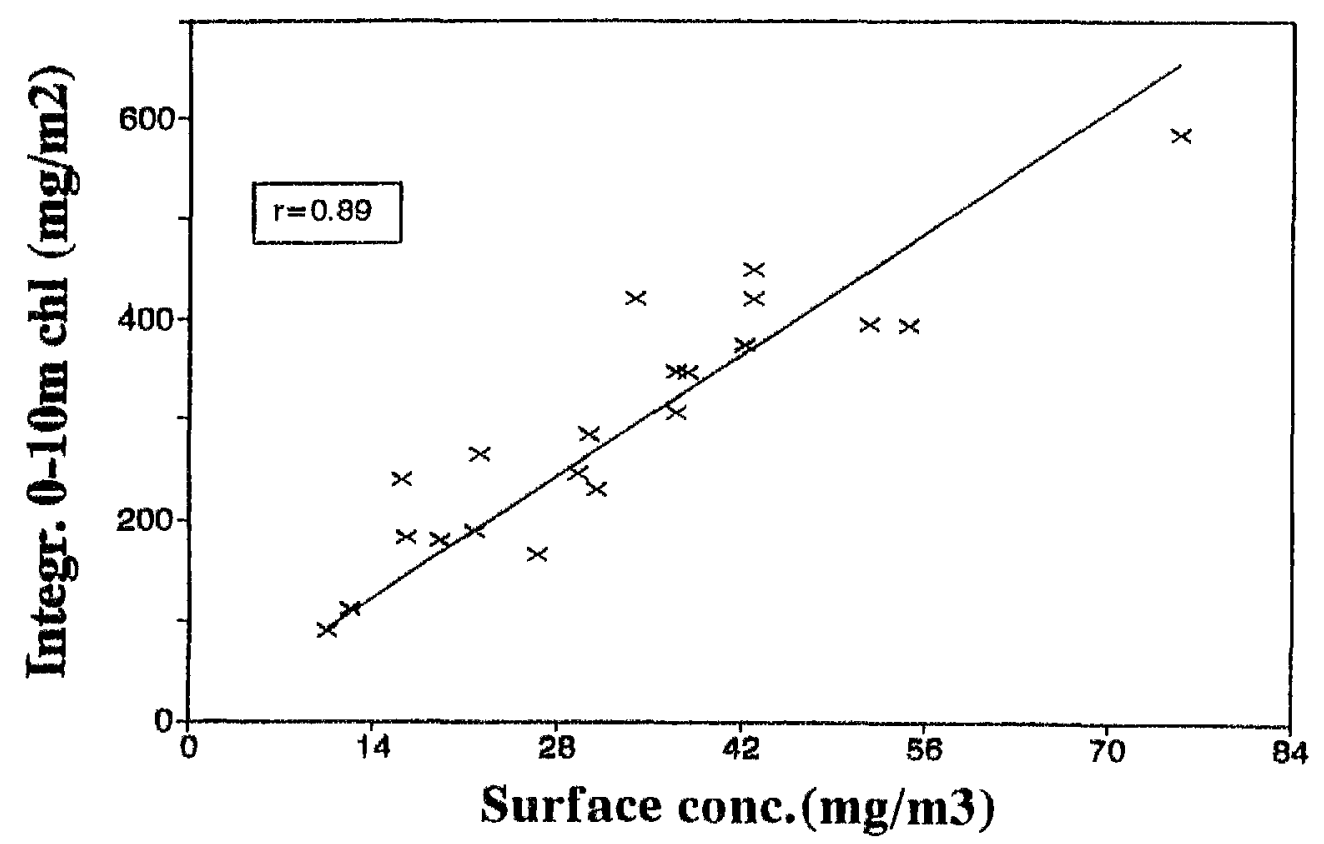

Fig. 9. The correlation between surface $\mathrm{Chl}$ concentration and integrated $0-10 \mathrm{~m}$ water column chlorophyll concentration, recorded on 9 April, 1991 (Y.Z.Yacobi, unpublished).

concentration period; Mayo et al., 1994), are not completely disappointing-the information derived is unique and could not be gained from any other source.

Our results suggest that for real-time monitoring of phytoplankton bloom development, even images taken from the NOAA satellite AVHRR with spatial resolution of $1 \times 1 \mathrm{~km}$, can be used as an early warning monitoring system.

\section{Conclusions}

In the long run, the full potential of remote sensing for investigation of inland waters will be realized through the construction of physically based models. Those models should describe the scattering and absorption of radiation, and the relationships between constituent concentrations and the optical properties of inland waters. However, over short and medium time spans, this approach may be difficult to implement due to lack of information on the essential inherent parameter-specific optical properties of inland waters. We are therefore left with the option of using more empirical approaches, of which spectral indices constitute the major category. For such an approach, the observed spectral features and understanding of their sensitivity to variation in each constituent concentration are extremely important. The findings of this work support earlier results that the spectral range from green to near IR is a suitable source for algorithm construction for Chl assessment in inland and productive coastal waters (Gitelson et al., 1986, 1993a,b, 1994a,b; Fischer and Kronfeld, 1990; Quibell, 1992; Dekker, 1993; Rundquist et al., 1995a,b). The novel algorithms devised in this study enhanced the precision of Chl determination and thus surpassed the existing algorithms for use in Lake Kinneret during Peridinium bloom. Using Lake Kinneret as a case study, we assume that the developed models can be applied for remote assessment of Chl in other eutrophic inland waters. 
For the remote assessment of $\mathrm{Chl}$ in inland productive waters, a sensor for the measurement of radiance with three spectral bands, 670 and $710 \mathrm{~nm}$ (with bandwidth $10 \mathrm{~nm}$ ) and $850 \mathrm{~nm}$ (with bandwidth up to $40 \mathrm{~nm}$ ), should be sufficient.

The stability of the models depends on the temporal and spatial stability of the inherent optical properties of the constituents. Further investigation is required in order to clarify whether the parameters of the models are constant with time in the sampling area.

Remotely operated sensors for real-time monitoring of water quality may not only be carried on satellites and aircraft, but may be installed on ships or in a stationary observatory. These shipboard or stationary platforms should carry imaging sensors with a few specific narrow spectral bands. They are relatively inexpensive and are not limited by uncontrolled restrictions, such as the timing of a satellite overpass, and can be deployed with more flexibility (with respect to both temporal and spatial scales). They seem particularly promising for monitoring relatively small areas of investigation, but can also cover large areas for synoptic mapping.

\section{Acknowledgements}

We would like to thank Dr Arkady Parparov for providing data on suspended matter, and Nir Koren and Sarah Chava for technical assistance. We would also thank an anonymous reviewer for instructive corrections. This work was supported by grants from the Israel Water Commissioner's Office, the Ministry of Science and Technology, and the Israel Academy of Sciences and Humanities.

\section{References}

Berman,T. (1972) Profiles of chlorophyll concentrations by in vivo fluorescence: some limnological applications. Limnol. Oceanogr., 17, 616-618.

Berman,T. and Elias, Y. (1973) Lake Kinneret: Synoptic studies of chlorophyll concentrations. In Tadmor,J. (ed.), Proceedings of the 4th Israel Ecology Society Conference. Jerusalem, pp. F17-19.

Berman, T. and Rodhe,W. (1971) Distribution and migration of Peridinium in Lake Kinneret. Mitt. Int. Ver. Limnol., 19, 266-276.

Bidigare,R.R., Ondrusek,M.E., Morrow,J.H. and Kiefer,D.A. (1990) In vivo absorption of algal pigments. SPIE Proc. Ocean Optics X, 1302, 290-302.

Dekker,A.G. (1993) Detection of the optical water quality parameters for eutrophic waters by high resolution remote sensing. $\mathrm{PhD}$ Thesis, Free University, Amsterdam, The Netherlands, $212 \mathrm{pp}$.

Dekker,A.G., Malthus,T.J., Wijnen,M.M. and Seyhan,E. (1992) The effect of spectral band width and positioning on the spectral signature analysis of inland waters. Remote Sensing Environ., 41, 211-226.

Doerffer,R. (1981) Factor analysis in ocean color interpretation. In Gower,J.F.R. (ed.), Oceanography from Space. Plenum Press, New York, pp. 339-345.

Fischer,J, and Kronfeld,V, (1990) Sun-stimulated chlorophyll fluorescence. 1: Influence of oceanic properties, Int. J. Remote Sensing, 11, 2125-2147.

Dubinsky,Z. and Berman,T. (1979) Seasonal changes in the spectral composition of downwelling irradiance in Lake Kinneret (Israel). Limnol. Oceanogr., 24, 652-663.

Dubinsky,Z. and Polna,M. (1976) Pigment composition during a Peridinium bloom in Lake Kinneret (Israel), Hydrobiologia, 51, 239-243.

Fraser,R.S., Ferrare,R.A., Kaufman, Y.J., Markham,B.L. and Mattoo,S. (1992) Algorithm for atmospheric corrections for aircraft and satellite imagery. Int. J. Remote Sensing, 13, 541-557.

George,D.G. and Heaney,S.I. (1978) Factors influencing the spatial distribution of phytoplankton in a small productive lake. J. Ecol, 66, 133-155.

Gitelson,A. (1992) The peak near $700 \mathrm{~nm}$ on reflectance spectra of algae and water: relationships of its magnitude and position with chlorophyll concentration. Int. J. Remote Sensing, 13, 3367-3373.

Gitelson,A. (1993a) Algorithms for remote sensing of phytoplankton pigments in inland waters. Adv. Space Res., 13, 197-201. 


\section{Y.Z.Yacobi, A.Gitelson and M.Mayo}

Gitelson,A. (1993b) The nature of the peak near $700 \mathrm{~nm}$ on the radiance spectra and its application for remote estimation of phytoplankton in inland waters. Opt. Eng. Remote Sensing, SPIE 1971, pp. 170-179.

Gitelson,A., Nikanorov,A.M., Sabo,G. and Szilagyi,F. (1986) Etude de la qualite des eaux de surface par teledetection. IAHS Publications, 157, 111-121.

Gitelson,A., Garbuzov,G., Szilagyi,F., Mittenzwey, K.-H., Karniela,A. and Kaiser,A. (1993a) Quantitative remote sensing methods for real-time monitoring inland water quality. Int. J. Remote Sensing, 14, 1269-1295.

Gitelson,A., Szilagyi,F, and Mittenzway,K. (1993b) Improving quantitative remote sensing for monitoring of inland water quality. Water Res., 7, 1185-1194.

Gitelso,A., Mayo, M. and Yacobi,Y.Z. (1994a) Signature analysis of reflectance spectra and its application for remote observations of the phytoplankton distribution in Lake Kinneret. In Mesures Physiques et Signatures en Teledetection. ISPRS 6th International Sypsoium, Val d'Isere, France, pp. 277-283.

Gitelson,A., Mayo,M., Yacobi,Y.Z., Parparov,A. and Berman,T. (1994b) The use of high spectral radiometer data for detection of low chlorophyll concentrations in Lake Kinneret. J. Plankton Res., 16, 993-1002.

GKSS (1986) The Use of Chlorophyll Fluorescence Measurements from Space for Separating Constituents of Sea Water. ESA Contract No. RFQ3-5059/84/NL/MD, Vol. II, Appendices. GKSS Research Centre.

Gordon,H. and Morel,A. (1983) Remote Assessment of Ocean Color for Interpretation of Satellite Visible Imagery. A Review. Springer-Verlag, New York, $114 \mathrm{pp.}$

Gower,J.F.R. (1980) Observations of in-situ fluorescence of chlorophyll- $a$ in Saanich Inlet. BoundaryLayer Meteorol., 18, 235-245.

Han,L., Rundquist,D.C., Liu,L.L., Fraser,R.N. and Schalles,J.F. (1995) The spectral responses of algal chlorophyll in water with varying levels of suspended sediment. Int. J. Remote Sensing, in press.

Heaney,S.I. and Epply,R.W. (1981) Light, temperature and nitrogen as interacting factors affecting diel vertical migrations of dinoflagellates in culture. J. Plankton Res., 3, 331-344.

Heaney,S.I. and Talling,J.F. (1980) Dynamic aspects of dinoflagellate distribution patterns in a small productive lake. J. Ecol., 68, 75-94.

Holm-Hansen,O., Lorenzen,C.J., Holmes, R.W. and Strickland,J.D.H. (1965) Fluorometric determination of chlorophyll. J. Cons. Int. Explor. Mer, 30, 3-15.

Kaufman,Y.J. (1993) Measurements of the aerosol optical thickness and the path radiance implications for aerosol remote sensing and atmospheric corrections. J. Geophys. Res., 98, 2677-2692.

Kaufman,Y.J. and Fraser,R.S. (1983) Light extinction by aerosol during summer air pollution. J. Appl. Meteorol., 22, 1964-1706.

Matthews,A.M. and Boxall,S.R. (1994) Novel algorithms for the determination of phytoplankton concentration and maturity. In Proceedings of the Second Thematic Conference on Remote Sensing for Marine and Coastal Environments, 31 January-2 February 1994, New Orleans, LA, USA. Environmental Research Institute of Michigan, Vol. 1, pp. I-173-I-180.

Mayo,M., Gitelson,A., Yacobi,Y.Z. and Ben-Avraham,Z. (1994) Chlorophyll distribution in Lake Kinneret determined from Landsat Thematic Mapper data. Int. J. Remote Sensing, 14, 175-182.

Neville,R.A. and Gower,J.F.R. (1977) Passive remote sensing of phytoplankton via chlorophyll- $a$ fluorescence. J. Geophys. Res., 82, 3487-3493.

Pollingher,U. (1986) Phytoplankton periodicity in a subtropical lake (Lake Kinneret, Israel). Hydrobiologia, 138, 127-138.

Pollingher,U. (1988) Freshwater armored dinoflagellates: growth, reproduction strategies, and population dynamics. In Sandgren,C.D. (ed.), Growth and Reproductive Strategies of Freshwater Phytoplankton. Cambridge University Press, pp. 134-174.

Pollingher,U. and Berman,T. (1975) Temporal and spatial patterns of dinofiagellate blooms in Lake Kinneret, Israel (1969-1974). Verh. Int. Ver. Limnol., 19, 1370-1382.

Pollingher,U. and Kimor,B. (1970) Seasonal and bathymetrical changes in the composition of the phytoplankton of Lake Tiberias based on biomass estimation during the years 1964-1967. Ministry of Agriculture. State of Israel. Sea Fish. Res. Stn Bull., 55, 3-20.

Quibell,G. (1992) Estimation chlorophyll concentrations using upwelling radiance from different freshwater algal genera. Int. J. Remote Sensing, 13, 2611-2621.

Ritchie,J.C. and Cooper,C.M. (1987) Comparison of Landsat MSS pixel array sizes for estimating water quality. Photogram. Eng. Remote Sensing, 53, 1549-1553.

Rundquist,D.C., Han,L., Schalles,J.F. and Peake,J.S. (1995a) Remote measurement of algal chlorophyll in surface waters: the case for the first derivative of reflectance near $690 \mathrm{~nm}$. Photogram. Eng. Remote Sensing, in press. 
Rundquist,D.C., Schalles,J.F. and Peake,J.S. (1995b) The response of volume reflectance to manipulated algal concentrations above bright and dark bottoms at various depths in an experimental pool. Geocart Int., in press.

Serruya,C. (ed.) (1978) Lake Kinneret, Monographie Biologicae. Dr W.Junk Publishers, The Hague, Vol. 32, $502 \mathrm{pp}$.

Talling,J.F. (1971) The underwater light climate as a controlling factor in the production ecology of freshwater phytoplankton. Mitt. Int. Ver. Limnol, 19, 214-243.

Vasilkov,A.P. and Kopelevich;O.V. (1982) The reasons of maximum at about $700 \mathrm{~nm}$ on radiance spectra of the sea. Oceanography, 22, 945-950.

Vos,W.L., Donze,M. and Bueteveld,H. (1986) On the reflectance spectrum of algae in water: The nature of the peak at $700 \mathrm{~nm}$ and its shift with varying concentration. Communication on Sanitary Engineering and Water Management, Delft, The Netherlands, Technical Report, 86-22.

Received on December 24, 1994; accepted on August 3, 1995 